\title{
Putting floristic thermophilization in forests into a conservation biology perspective: beyond mean trait approaches
}

\author{
Frédéric Gosselin ${ }^{1}$
}

Received: 20 February 2015 / Accepted: 27 October 2015 /Published online: 20 November 2015

(C) INRA and Springer-Verlag France 2015

\begin{abstract}
- Key message The use of mean characteristics of communities to infer absolute species variations may well constitute another "silent clash of paradigms" Austin (Oikos 86:170-178, 1999) in community ecology. We discuss this issue based on a recent paper on floristic thermophilization in forests.
\end{abstract}

Fifteen years ago, Austin (1999) denounced the lack of communication and coherence between different paradigms in ecology - with an emphasis on community ecology. I gave a further example of this shortcoming related to the analysis and interpretation of biotic homogenization (Gosselin 2012); while mean trait approaches related to niche theory have been used to quantify within-community biotic homogenization, they have no clear bearing on the extirpation of specialist species in a conservation biology context - despite what is often claimed. Hereafter, I discuss yet another, similar example of inconsistency between ecological paradigms, with the aim to ultimately better connect them.

Handling Editor: Laurent Bergès

Electronic supplementary material The online version of this article (doi:10.1007/s13595-015-0526-1) contains supplementary material, which is available to authorized users.

Frédéric Gosselin

frederic.gosselin@irstea.fr

Irstea, UR EFNO, Domaine des Barres,

F-45290 Nogent-sur-Vernisson, France
De Frenne et al. (2013) have proposed an interesting temporal analysis with respect to climate change of 1409 vegetation plots in European and North American forests. They found that the species composition on the plots indicates a "thermophilization" over time, i.e. an increase in mean species thermal preference. The authors also reveal a negative correlation between change in forest canopy cover and thermophilization. As regards plot species richness, it was stable in Europe and increasing in North America.

Although the study is interesting, I have serious doubts about the interpretation of the results. Indeed, the authors state that "these changes [related to thermophilization] reflect concurrent declines in species adapted to cooler conditions and increases in species adapted to warmer conditions" (p. 18561). To draw these conclusions, however, the authors do not analyze the species richness or abundance of cold-adapted or warmth-adapted species; rather, they interpret the cold (fifth percentile) and warm (95th percentile) extremes of the floristic temperature distribution of each plot as indicated by species thermal preferences. This method of interpretation is based on Figure S4 of De Frenne et al. (2013) and is problematic in two respects. The first limitation (L1) is that this method of interpretation only considers species that have a similar level of "specialization" with respect to temperature. The second limitation (L2) is due to the fact that the method used is relative; exactly the same thermophilization statistics would be obtained even if we replicated each species in the community $n$ times. As with any other mean trait approach (Gosselin 2012), De Frenne et al.'s results for thermophilization may therefore have no direct link with 
Fig. 1 Three scenarios of floristic variation that give qualitatively similar results in terms of thermophilization - an increase of all three quantiles 5, 50 and $95 \%$ of the floristic temperature distributions - as those observed by De Frenne et al. (2013) in Europe yet correspond to three different ecological

interpretations: (from top to bottom) (i) an increase in warmthadapted species and a decrease in cold-adapted species, (ii) a decrease in cold-adapted species and an increase in generalist species and (iii) an increase in warmth-adapted species and a decrease in generalist species. Left: thermophilization indicesi.e. differences with original situations - for temperature quantiles 5, 50 (median) and $95 \%$. Right: abundanceactually here, proportional to the number of species - in the four ecological groups simulated (temperature generalist in green with diamond symbol, coldadapted in blue with square symbol, intermediate temperatures adapted in brown with circle symbol and warmadapted species in red with triangle symbol), in the past (thin plain curves) and now (thick dashed curves)
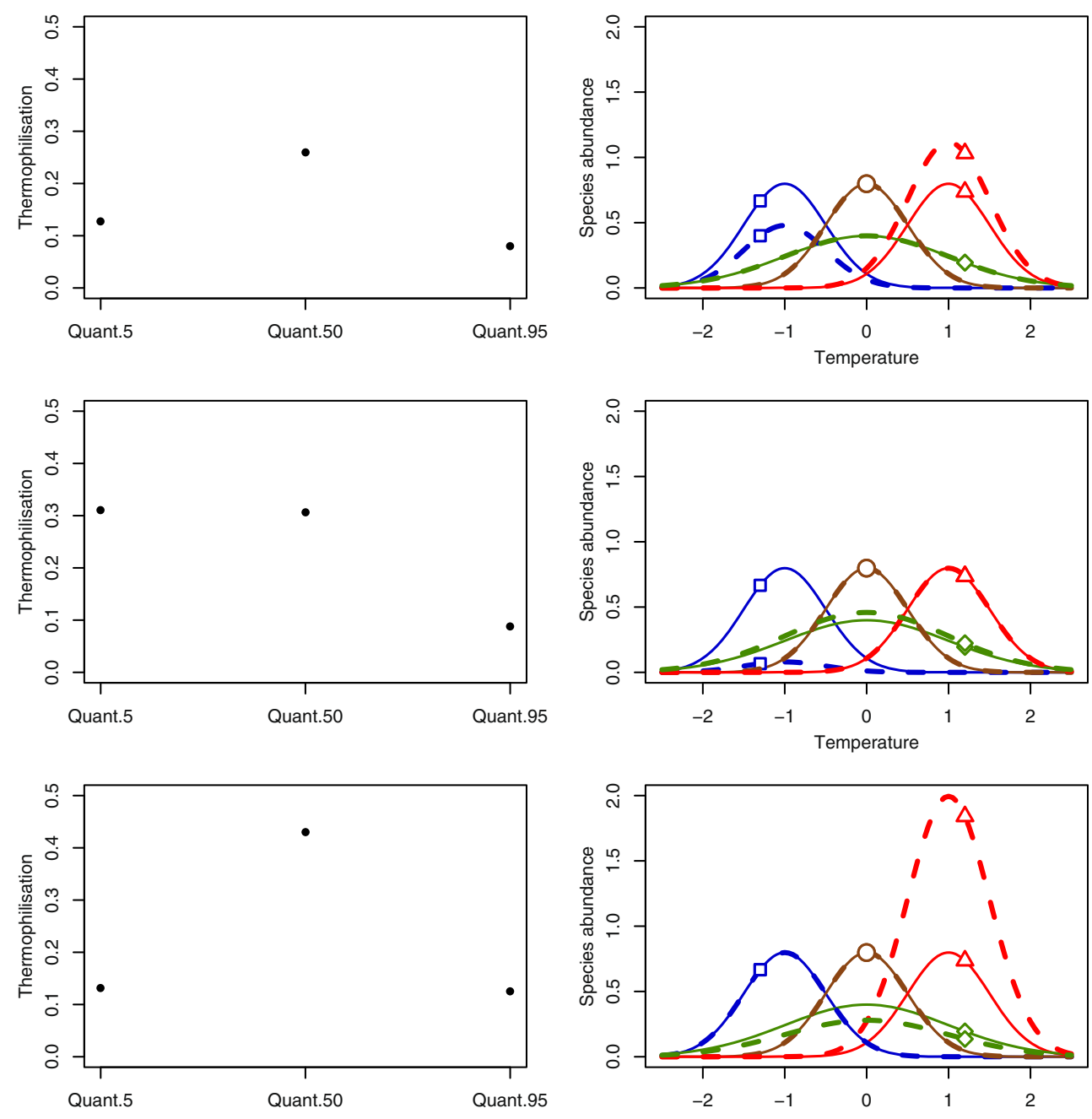

actual declines and increases in cold-adapted and warmthadapted species - if we interpret these declines and increases in terms of absolute frequency or absolute abundance changes of these species. Only analyses of absolute metrics (species richness, abundance, etc.) for more precisely defined groups of species or multi-species analyses of abundance will indicate what is actually occurring (Gosselin 2012). For example, the results in Europe could just as well be explained by (i) an increase in warmth-adapted species and a decrease in cold-adapted species, as proposed by De Frenne et al., (ii) a decrease in cold-adapted species and an increase in generalist species, (iii) an increase in warmth-adapted species and a decrease in generalist species, (iv) an increase in all the species groups, but with a higher relative increase in warmth-adapted species and (v) a decrease in all the species groups, but with a lower relative increase in warmth-adapted species (cf. Figs. 1 and
2 based on simulations described in Supplementary Material 1). Points (ii) and (iii) above illustrate (L1) while points (iv) and (v) are related to (L2).

Similarly, the link between canopy cover variation and thermophilization has no direct bearing on the absolute variation in species abundance or richness, whatever their temperature preference, contrary to what De Frenne et al. state - e.g. "the increase in warm-adapted species was consistently lower in plots that increased in canopy cover compared with plots that became more open over time". Yet De Frenne et al. do not analyze the relationship between canopy cover variation and changes in species richness or absolute abundance of species. The net effect of variations in canopy cover on floristic diversity can be due to many mechanisms other than temperature - such as light and water balance - and can be negative in some circumstances (Kwiatkowska 1994; Spyreas and Matthews 2006) and/or 
Fig. 2 Three scenarios of floristic variation that give qualitatively similar results in terms of thermophilization - an increase of all three quantiles 5, 50 and $95 \%$ of the floristic temperature distributions - as those observed by De Frenne et al. (2013) in Europe yet correspond to three different ecological interpretations: (from top to bottom) (i) an increase in warmthadapted species and a decrease in cold-adapted species, (ii) an increase in all the species groups and (iii) a decrease in all the species groups. Left: thermophilization indices-i.e. differences with original situations - for temperature quantiles 5, 50 (median) and $95 \%$. Right: abundanceactually here, proportional to the number of species - in the four ecological groups simulated (temperature generalist in green with diamond symbol, coldadapted in blue with square symbol, intermediate temperatures adapted in brown with circle symbol and warmadapted species in red with triangle symbol), in the past (thin plain curves) and now (thick dashed curves)
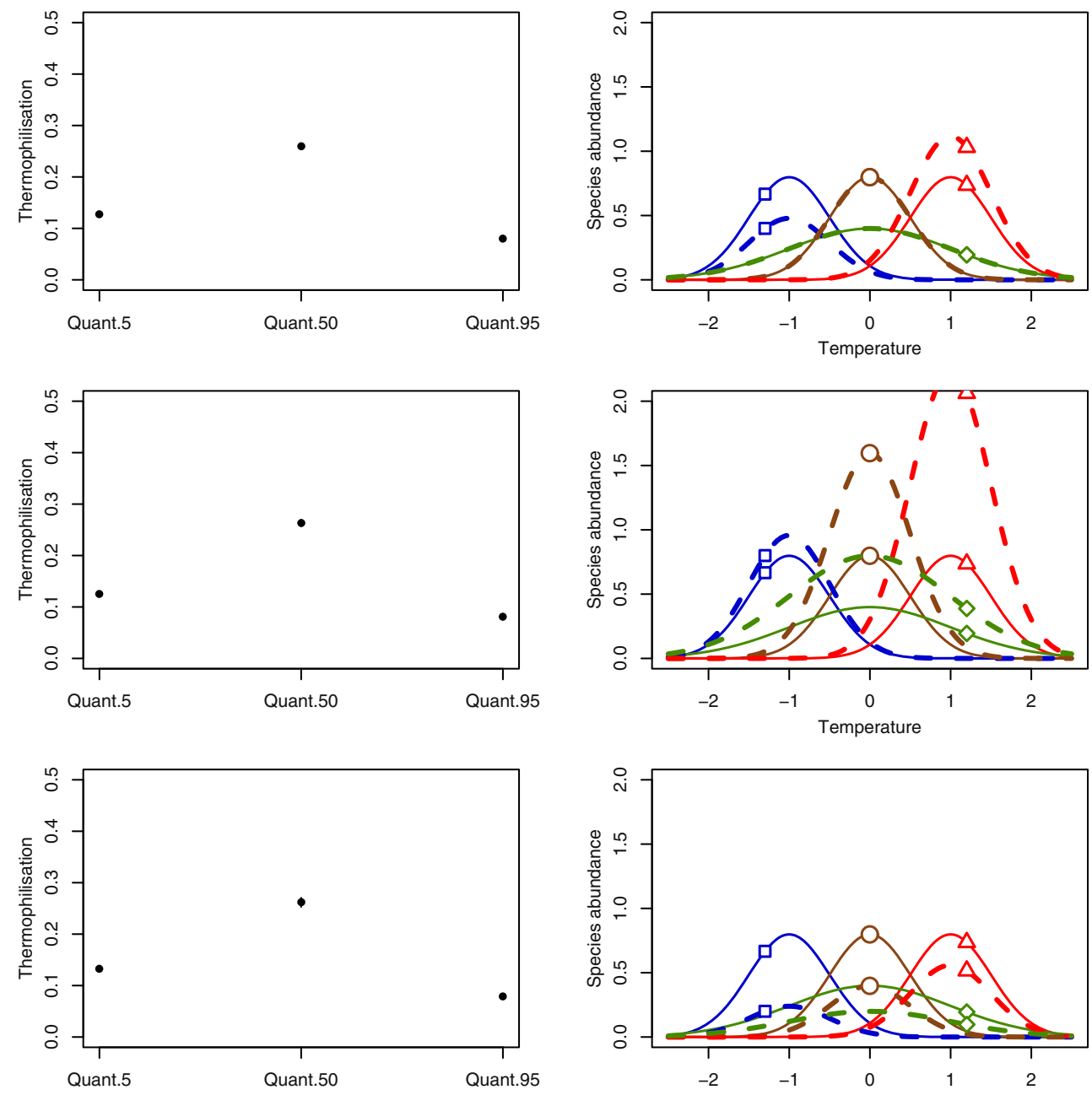

depend on ecological groups (Barbier et al. 2009; Zilliox and Gosselin 2014) and ecological contexts (Zilliox and Gosselin 2014).

This means that ecologists treating conservation issues based on mean trait analyses - or other metrics based on relative abundance - should take care to consider absolute metrics as welle.g. richness, abundance and viability. Indeed, while niche theory in community ecology could to some extent be coherent with mean trait approaches, the two main paradigms of conservation biology - the minimum viable population paradigm and the declining population paradigm (Caughley 1994) - require more absolute metrics as exemplified by cases (iv) and (v) above. Otherwise, we may very well witness another silent clash of paradigms, similar to the one deplored by Austin (1999).

Acknowledgments I am grateful to Vicki Moore for having checked the correctness of the English grammar and Frédéric Archaux, Marie
Baltzinger and Basile Herpigny for re-reading a previous version of the paper. I am also very grateful to the editors and reviewers - particularly one reviewer who was so kind as to propose the code for one of the figures. This research was granted by the French ministry in charge of the Ecology through the DEB-Irstea convention (Action S).

\section{References}

Austin MP (1999) A silent clash of paradigms: some inconsistencies in community ecology. Oikos 86:170-178. doi:10.2307/3546582

Barbier S, Chevalier R, Loussot P, Bergès L, Gosselin F (2009) Improving biodiversity indicators of sustainable forest management: tree genus abundance rather than tree genus richness and dominance for understory vegetation in French lowland oak hornbeam forests. For Ecol Manag 258:S176-S186. doi:10.1016/j.foreco.2009.09.004

Caughley G (1994) Directions in conservation biology. J Anim Ecol 63: 215-244. doi: $10.2307 / 5542$

De Frenne P, Rodríguez-Sánchez F, Coomes DA, Baeten L, Verstraeten $\mathrm{G}$, Vellen M, Bernhardt-Römermann M, Brown CD, Brunet J, 
Cornelis J, Decocq GM, Dierschke H, Eriksson O, Gilliam FS, Hédl R, Heinken T, Hermy M (2013) Microclimate moderates plant responses to macroclimate warming. Proc Natl Acad Sci U S A 110: 18561-18565. doi:10.1073/pnas.1311190110

Gosselin F (2012) Improving approaches to the analysis of functional and taxonomic biotic homogenization: beyond mean specialization. $\mathrm{J}$ Ecol 100:1289-1295. doi:10.1111/j.1600-0587.2013.00279.x

Kwiatkowska AJ (1994) Changes in the species richness, spatial pattern and species frequency associated with the decline of oak forest. Vegetatio 112:171-180. doi:10.1007/BF00044691
Spyreas G, Matthews JW (2006) Floristic conservation value, nested understory floras, and the development of secondgrowth forest. Ecol Appl 16:1351-1366. doi:10.1890/10510761

Zilliox C, Gosselin F (2014) Tree species diversity and abundance as indicators of understory diversity in French mountain forests: variations of the relationship in geographical and ecological space. For Ecol Manag 321:105-116. doi:10.1016/j. foreco.2013.07.049 